
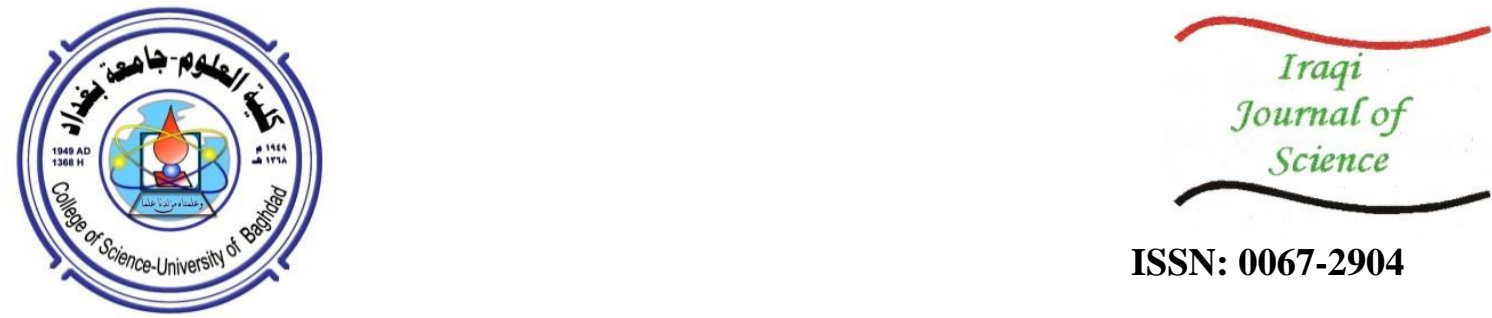

ISSN: 0067-2904

\title{
Influence of the Distance between Focusing Lens and Target Surface on the Characteristics of Laser-excited Lead Plasma
}

\author{
Qusay Adnan Abbas \\ Department of Physics, College of Science, University of Baghdad, Baghdad, Iraq
}

Received: 24/11/2020

Accepted: $30 / 8 / 2021$

\begin{abstract}
:
The present work investigated the effect of distance from target surface on the parameters of lead plasma excited by $1064 \mathrm{~nm}$ Q-switched Nd:YAG laser. The excitation was conducted in air, at atmospheric pressure, with pulse length of $5 \mathrm{~ns}$, and at different pulse laser energies. Electron temperature was calculated by Boltzmann plot method based on the PbI emission spectral lines ( $369.03 \mathrm{~nm}, 416.98$ $\mathrm{nm}, 523.48$, and $561.94 \mathrm{~nm}$ ). The $\mathrm{PbI}$ lines were recorded at different distances from the target surface at laser pulse energies of 260 and $280 \mathrm{~mJ}$. The emission intensity of plasma increased with increasing the lens-to-target distance. The results also detected an increase in electron temperature with increasing the distance between the focal lens and the surface of the target in all laser energies under study. In addition, the electron number density was determined by using the Stark broadening method. The data illustrated that the electron number density was increased with increasing the distance from target surface, reaching the maximum at a distance of $11 \mathrm{~cm}$ for all pulse laser energy levels under study.
\end{abstract}

Keywords: LIBS, Plasma Temperature, Electron number Density, Stark Broadening, Boltzmann plot method.

\section{تأثير المسافة بين الليزر والههف على خصائص بلازما الرصاص المنتجة بالليزر}

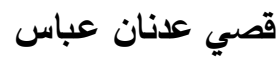 \\ قسم الفيزياء،كلية العلوم ، جامعه بغداد، بغداد، العراق.
}

الخلاصة

في العمل الحالي تم دراسة تأثير المسافة عن سطح هدف الرصاص على معلمات البلازما الرصاص المستحثة

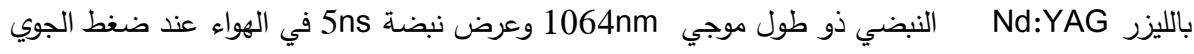

Boltzmann plot الاعتيادي وبطاق بضة مختلفة. تم حساب درجة حرارة الاكترون بأستخدام طريقات

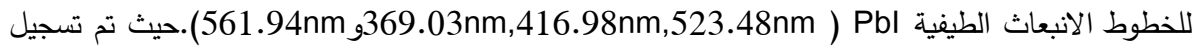

خطوط الانبعاث Pb عند مسافات مختلفة عن سطح الهدف وعند طاقات الليزر 280 mJ 260mJ.

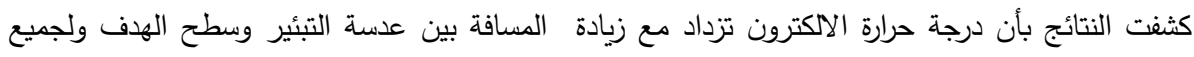

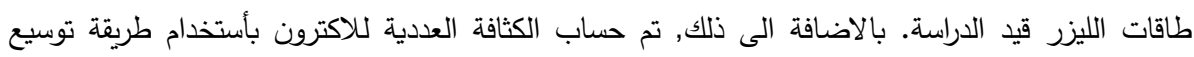

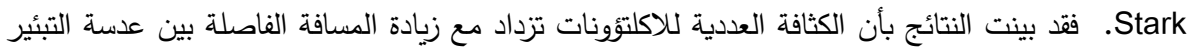

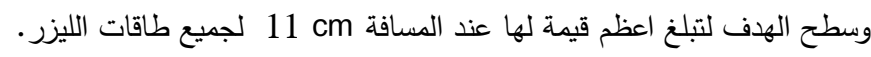

Email: Qusay.a@sc.uobaghdad.edu.iq. 


\section{Introduction}

In recent years, laser induced plasma spectroscopy (LIPS), or laser induced breakdown spectroscopy (LIBS), has been widely studied, as shown by many experimental and theoretical researches published on the topic [1-3]. LIBS has been increasingly involved in many research areas; for example, material production, biomedicine, military industry, pharmaceuticals, environmental monitoring, space applications, and diagnostic techniques $[2,4,5]$. The main activity of LIBS is the focusing of highly energetic laser pulses produced from a pulsed laser source on the target surface. Therefore, an approximately neutral plasma plume containing ions, electrons, atoms, or molecules is created on the surface of the target. The guided laser beam results in the evaporation, atomization, and ionization of the target's surface content, where the emitted radiation is used to detect the elemental composition of the samples [2,6]. This technique has several advantages over other traditional techniques of atomic emission spectroscopy; it is applicable to the study of conducting and non-conducting target samples and does not require sample preparation [4].

LIBS is used to calculate the temperature of the electrons and the number of plasma plume densities produced at the front of the target surface [2]. Most studies that were addressing LIBS temperature reported that the temperature of electrons appears to increase as laser wavelength, laser energy, pulse width, and ambient pressure increase [2].

Hongbing et al.[4] investigated laser-produced Mg plasma in the atmospheric air by a 1064 nm Nd:YAG laser. By employing Boltzmann plot method and the Stark expansion method, electron temperature and electron number density were calculated, respectively. They found that, along with the distance of the plasma expansion, electron temperature decreased with the increase in laser energy, whereas electron number density increased. Wang et al.[7] studied the effect of the distance between the target surface and the focusing lens on the temperature of $\mathrm{Cu}$ plasma caused by atmospheric Nd:YAG. They also applied Boltzmann plot method to calculate electron temperature. The results illustrated that, with the increase in lens-target distance, electron temperature firstly rose, and then dropped.

This work reports on the investigation of lead plasma generated by a $1064 \mathrm{~nm}$ Q-switched Nd:YAG laser in atmospheric air. We used Boltzmann plot method for determining electron temperature and Stark broadening method for determining electron number density of the produced $\mathrm{Pb}$ plasma. We report the effects of the distance between the focusing lens and target surface on these two parameters .

\section{Materials and Methods}

Figure 1 illustrates a schematic representation of the experimental arrangement of LIBS. The Pb plasma plume was created at atmospheric air from a lead target exposed to a pulse Nd:YAG laser with $1064 \mathrm{~nm}$ wavelength, $10 \mathrm{~ns}$ pulse duration, and two levels of pulsed laser energy $(260,280) \mathrm{mJ})$. A quartz lens with $15 \mathrm{~cm}$ focal length was utilized to focus the laser beam on the target surface to create a spot area of $1 \mathrm{~mm}^{2}$. The lens was placed at a distance of $9,10,11$, or $12 \mathrm{~cm}$ in order to understand plasma characteristics produced by different energies.

The $\mathrm{Pb}$ target's material purity was nearly $99.99 \%$, which was previously well polished before being exposed to the laser beam.

The emitted spectra of the $\mathrm{Pb}$ plasma plume were collected by an optical fiber located at $45^{\circ}$ of the laser light direction. The optical fiber was coupled to a THOR spectrometer. The experiment was performed under air and ambient pressure at room temperature. 


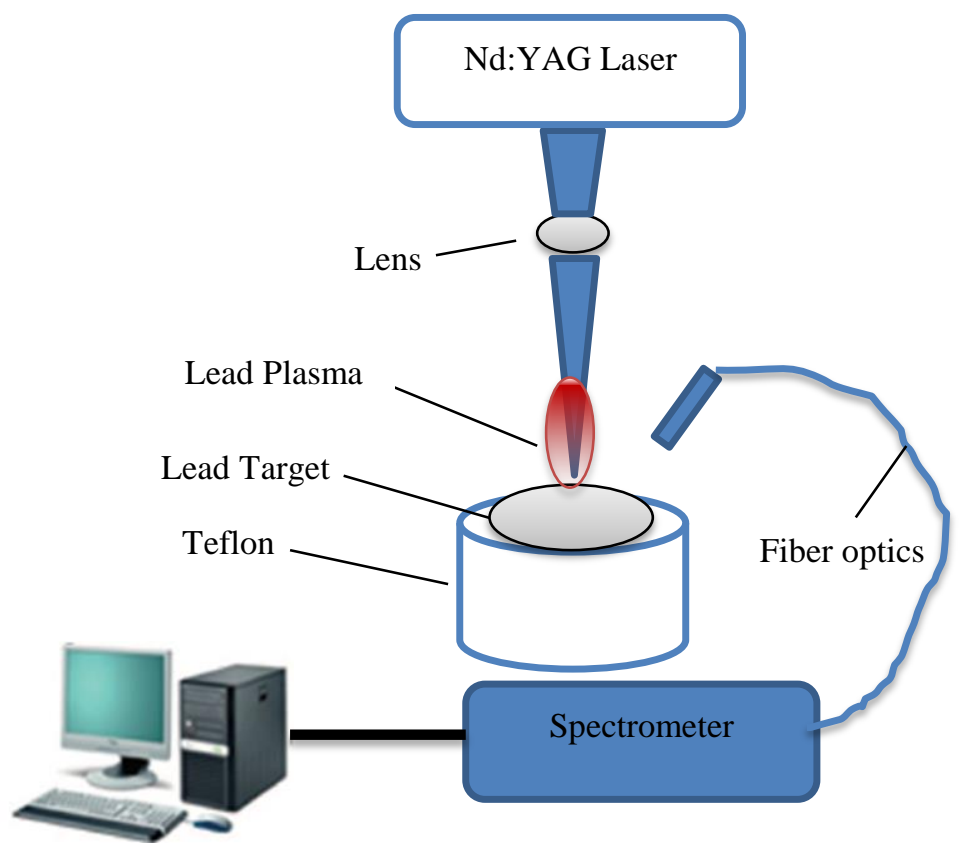

Figure 1-Schematic drawing of the experimental arrangement.

\section{Results and Discussion}

\subsection{Emission Spectra of Lead Plasma}

As a Q-switched Nd:YAG laser focuses at atmospheric pressure on a Pd target surface, emission intensity in the focal spot induces rapid local heating on the target surface of the $\mathrm{Pb}$ and creates a plasma that contains electrons, ions, atoms and molecules. Valuable references for improving the analysis techniques in the field of LIBS can be given by adjusting the distance between the focusing laser lens and the target surface. Two pulsed laser energies (260 and $280 \mathrm{~mJ}$ ) at $9 \mathrm{~cm}$ to $12 \mathrm{~cm}$ with a rate of $1 \mathrm{~cm}$ were used to understand the effect of the distance between the focusing lens and target surface on the $\mathrm{Pb}$ plasma parameters. Figures 2, 3, 4, and 5 illustrate the influence of laser energy on the emission spectra of $\mathrm{Pd}$ plasma, recorded at different lens-to-target distances. The spectra detected in these figures show many peaks of neutral $\mathrm{Pb}(\mathrm{Pb} \mathrm{I})$ at the wavelengths of 357.12, 363.47, 369.03, 371.89, 379.92, 395.86, 408.73, 416.98, 421.295, 511.08, 523.49, 539.52, 561.94, 573.66, 701.64, and $531.01 \mathrm{~nm}$. The neutral emission lines of H I (at wavelength $434.04 \mathrm{~nm}$ ) and the two peaks of $\mathrm{H}_{2} \mathrm{I}$ (at wavelengths 600.28 and $656.27 \mathrm{~nm}$ ) also appear in these spectra. All levels of peak intensity increased with the increase in laser energy. The increase in absorbing energy of laser by the particles generated in front of the target was responsible for the increase in the line emission intensity. Consequently, these spectra indicate that the generated $\mathrm{Pb}$ plasma contained only atomic $\mathrm{Pb}$ emission lines, whereas no ionic emission of $\mathrm{Pb}$ appeared. This fact could be explained according to plasma generation processes, which occur within a very short time of less than one millisecond before atomization. Thus, the electrons extruded by atoms during the ionization are further arrested by ions through the recombination process. Therefore, the ions liberate their energy as photon emission due to recombination [8]. In addition, $\mathrm{Pb}$ atoms require high energy to be ionized (i.e. have high ionization energy)and thus the possibility of their ionization is low. Anyway, there are other features that can be noted from these figures. It is easy to note that the spectral line intensity increases to become maximum at the distance of $12 \mathrm{~cm}$ (below the focal length). The change of the lens-to-target distance is equal to the variation of the irradiance of the focused laser pulse beam. The effect of the variation of the distance between the focusing lens and surface target is similar to changing the spot size of focused laser beam in focusing geometry, where the longer distance is corresponding to smaller spot size, while the larger spot size occurs in the shorter distance 
[7]. Therefore, the emission intensity of plasma spectra increases with increasing the lens-totarget distance.

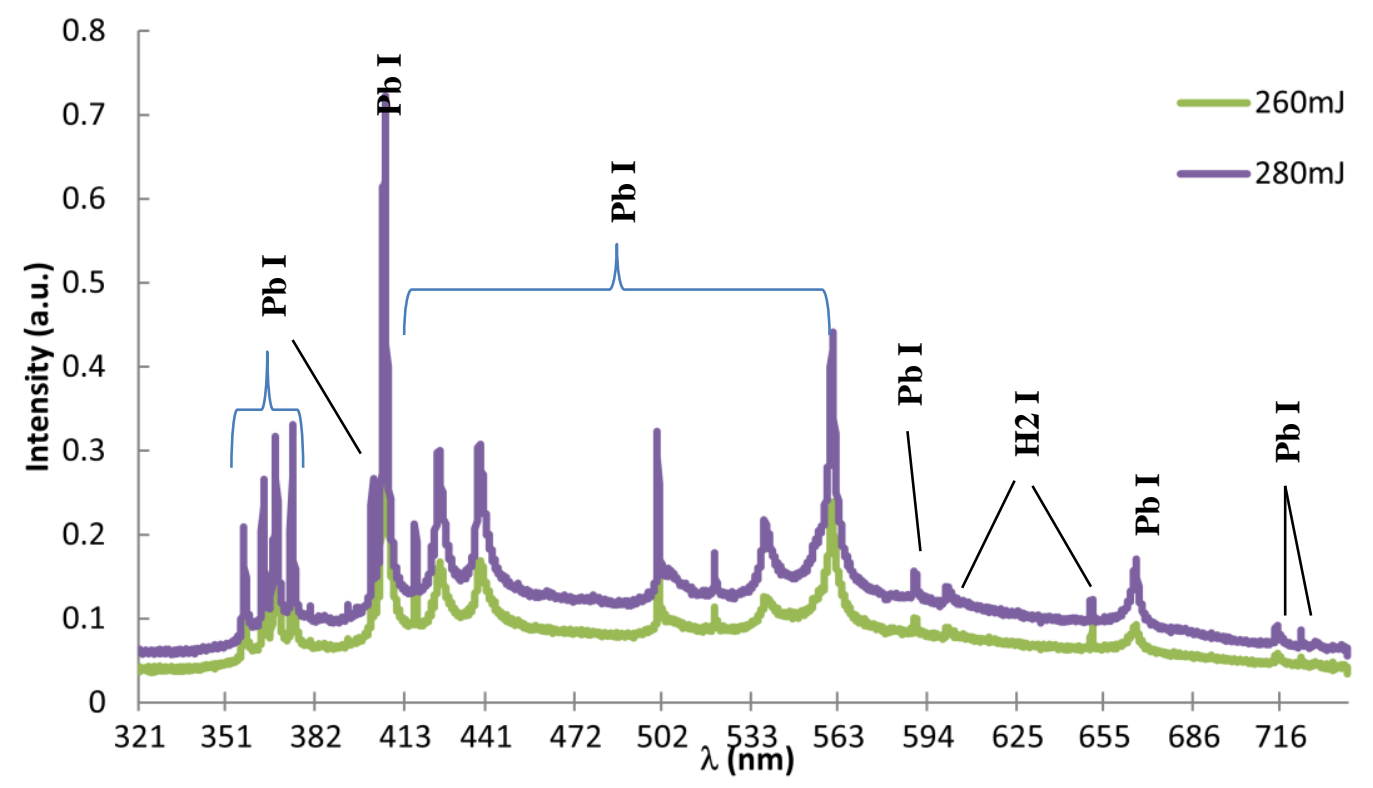

Figure 2: Emission spectrum of Lead plasma that detected for wavelength range 320$740 \mathrm{~nm}$ at different laser energy and in distance $9 \mathrm{~cm}$ between focusing lens and target surface.

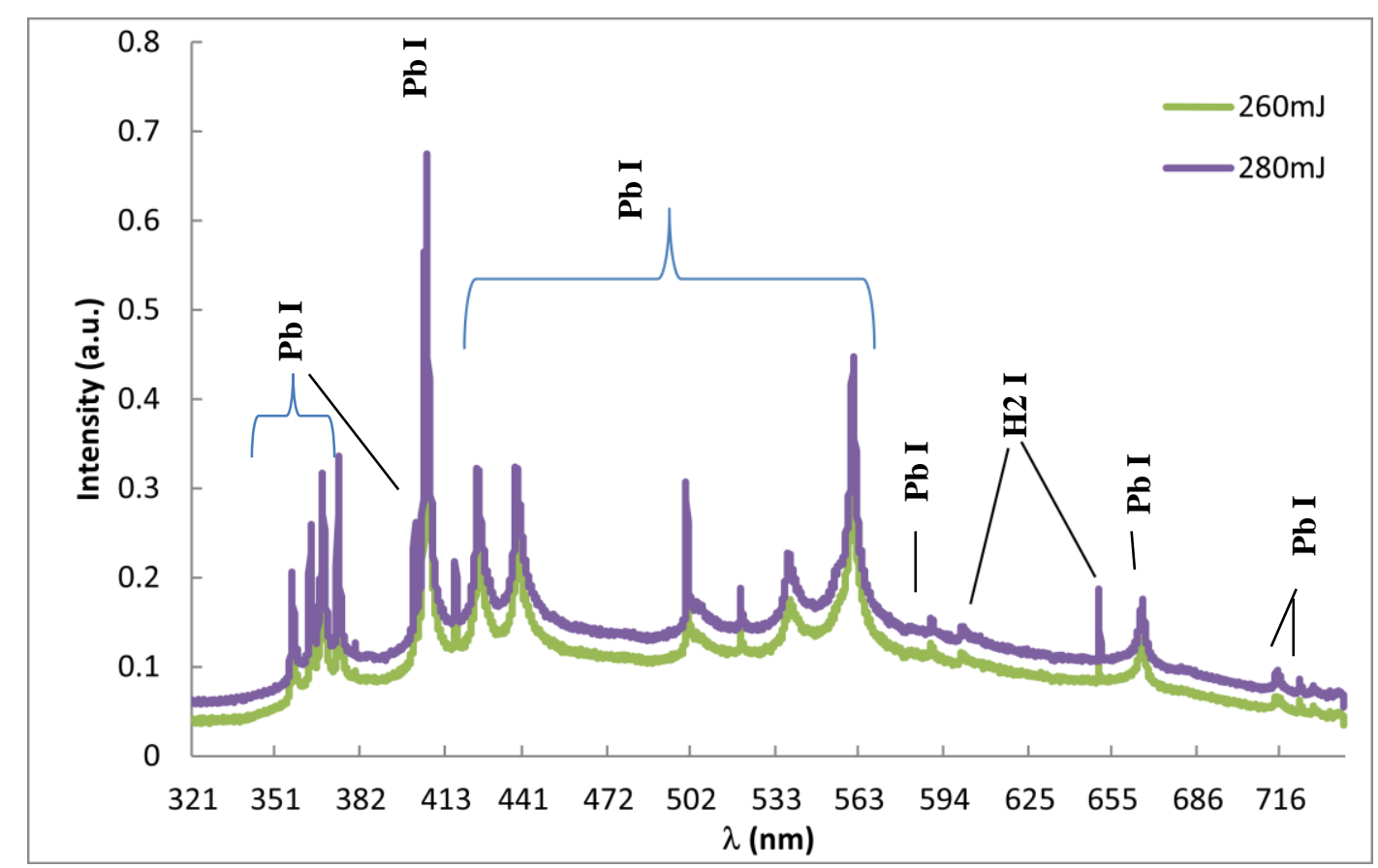

Figure 3: Emission spectrum of Lead plasma that detected for wavelength range $320-740 \mathrm{~nm}$ at different laser energy and in distance $10 \mathrm{~cm}$ between focusing lens and target surface. 


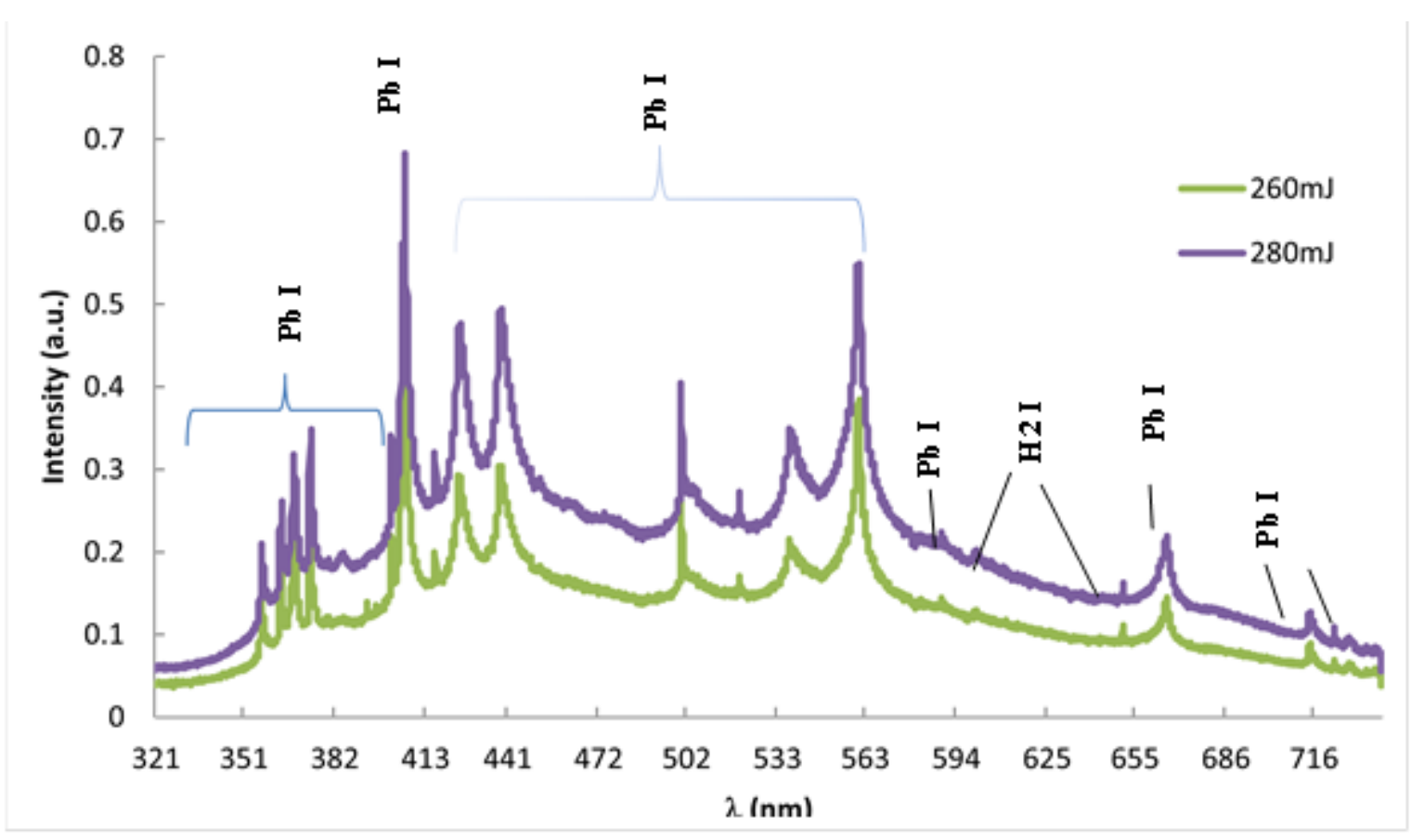

Figure (4): Emission spectrum of Lead plasma that detected for wavelength range 320 $740 \mathrm{~nm}$ at different laser energy and in $11 \mathrm{~cm}$ between focusing lens and target surface.

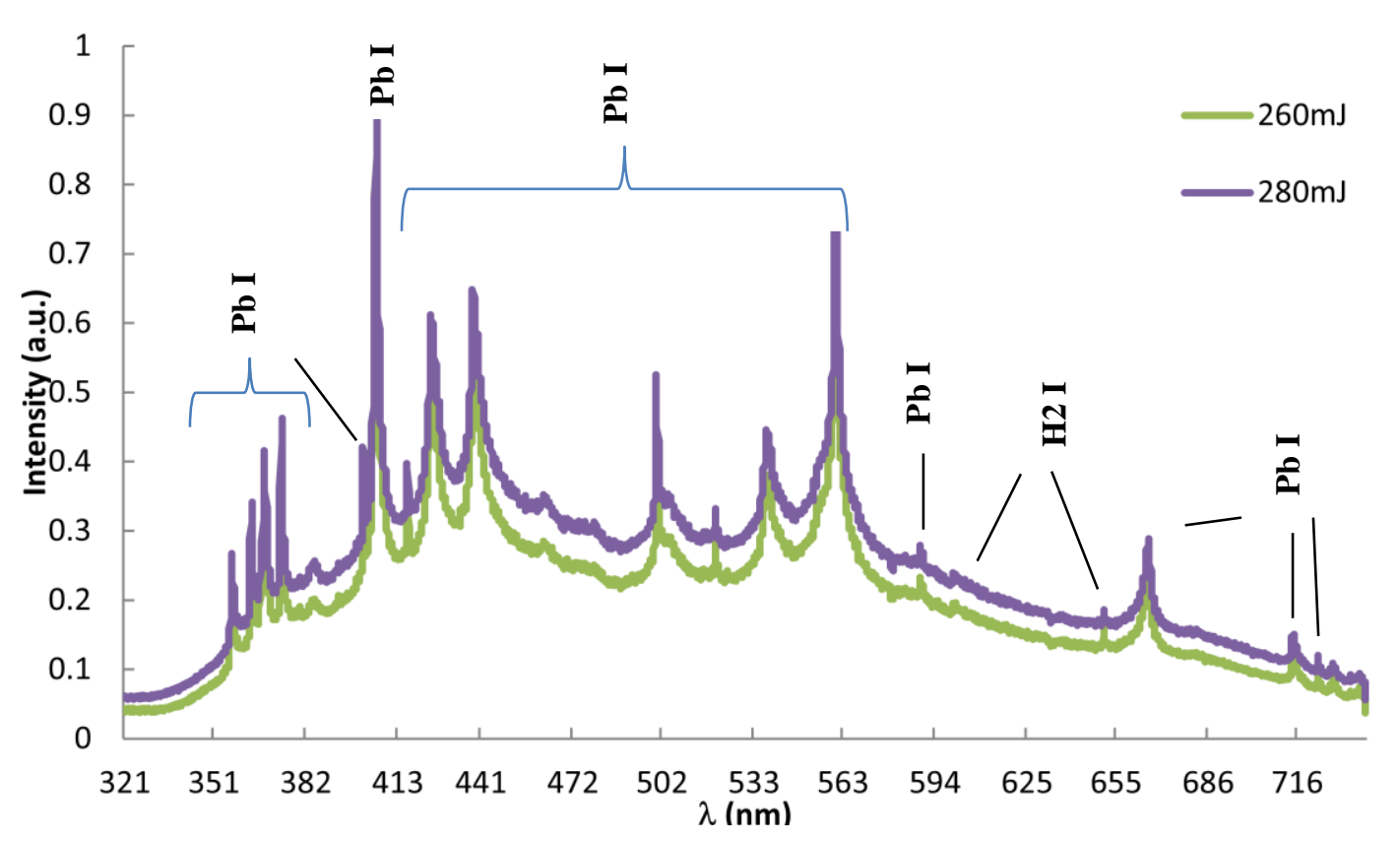

Figure 5: Emission spectrum of Lead plasma that detected for wavelength range 320-740nm at different laser energy and in distance $12 \mathrm{~cm}$ between focusing lens and target surface.

\subsection{Measurement of Temperature and Number Density of Electrons}

In the present work, emission spectral lines of lead were used to determine the electron temperature $\left(\mathrm{T}_{\mathrm{e}}\right)$ and electron number density $\left(\mathrm{n}_{\mathrm{e}}\right)$. These plasma characteristics are independent of each other, if one can consider that the local thermal equilibrium is satisfied. The most frequent method for calculating the $T_{e}$ from relative intensities of the observed lines 
is the Boltzmann plot, which is generally proportional to the population of the related upper levels, as follows [9-11]:

Table 1

\begin{tabular}{|c|c|c|c|c|}
\hline Atom/ Ion & $\begin{array}{c}\text { Wavelength } \\
(\mathrm{nm})\end{array}$ & $\mathrm{Ag}\left(\mathrm{sec}^{-1}\right)$ & Lower Level Energy (eV) & Upper Level Energy (eV) \\
\hline $\mathrm{Pb} \mathrm{I}$ & 369.034 & $2.24 \mathrm{E}+08$ & 1.453 & 4.812 \\
\hline $\mathrm{Pb} \mathrm{I}$ & 416.984 & $6.00 \mathrm{E}+06$ & 2.660 & 5.634 \\
\hline $\mathrm{Pb} \mathrm{I}$ & 523.486 & $3.52 \mathrm{E}+08$ & 4.455 & 6.823 \\
\hline $\mathrm{Pb} \mathrm{I}$ & 561.944 & $2.54 \mathrm{E}+08$ & 5.055 & 7.261 \\
\hline \multicolumn{5}{|c}{$\ln \left(\frac{\mathrm{I}_{\mathrm{Z}} \lambda_{\mathrm{ki}, Z}}{\mathrm{~g}_{\mathrm{k}, Z} \mathrm{~A}_{\mathrm{ki}, Z}}\right)=-\frac{1}{\mathrm{kT}_{\mathrm{e}}} \mathrm{E}_{\mathrm{kZ}}+\ln \left(\frac{\mathrm{hcL} \mathrm{L}_{\mathrm{n}, Z}}{4 \pi \mathrm{p}_{\mathrm{z}}}\right)$}
\end{tabular}

Here, $\mathrm{Z}, \mathrm{h}, \mathrm{k}, \mathrm{c}, \mathrm{L}, \mathrm{E}_{\mathrm{k}, \mathrm{z}}$, and $\mathrm{g}_{\mathrm{k}, \mathrm{Z}}$ refer to the ionization state of the species (where $\mathrm{z}=0$ and 1 correspond to the neutral and singly ionized atoms, respectively), Planck constant, Boltzmann constant, speed of light, characteristic length of the plasma, the energy, and degeneracy of the upper energy level $\mathrm{k}$, respectively. $\mathrm{P}_{\mathrm{Z}}$ is the partition function of the species in the ionization stage $Z . I_{Z}$ is the integrated intensity of a spectral line occurring between the upper energy level $\mathrm{k}$ and the lower energy level $\mathrm{i}$ of the species in the ionization stage $\mathrm{Z}$ in the optically thin plasma. A plot of $\ln \left(\frac{\mathrm{I}_{\mathrm{z}} \lambda_{\mathrm{ki}, \mathrm{z}}}{\mathrm{g}_{\mathrm{k}, \mathrm{z}} A_{\mathrm{ki}, \mathrm{z}}}\right)$ versus $\mathrm{E}_{\mathrm{k}}$ gives a straight line of slope $1 / \mathrm{kT}_{\mathrm{e}}$. According to equation (1) and different spectroscopic parameters of identified lead emission lines, brought from the National Institute of Standards and Technology (NIST) database tabulated in table (1), the influence of laser pulse energy on the electron temperature was calculated in different focusing lens -target distance and plotted in figure (6).

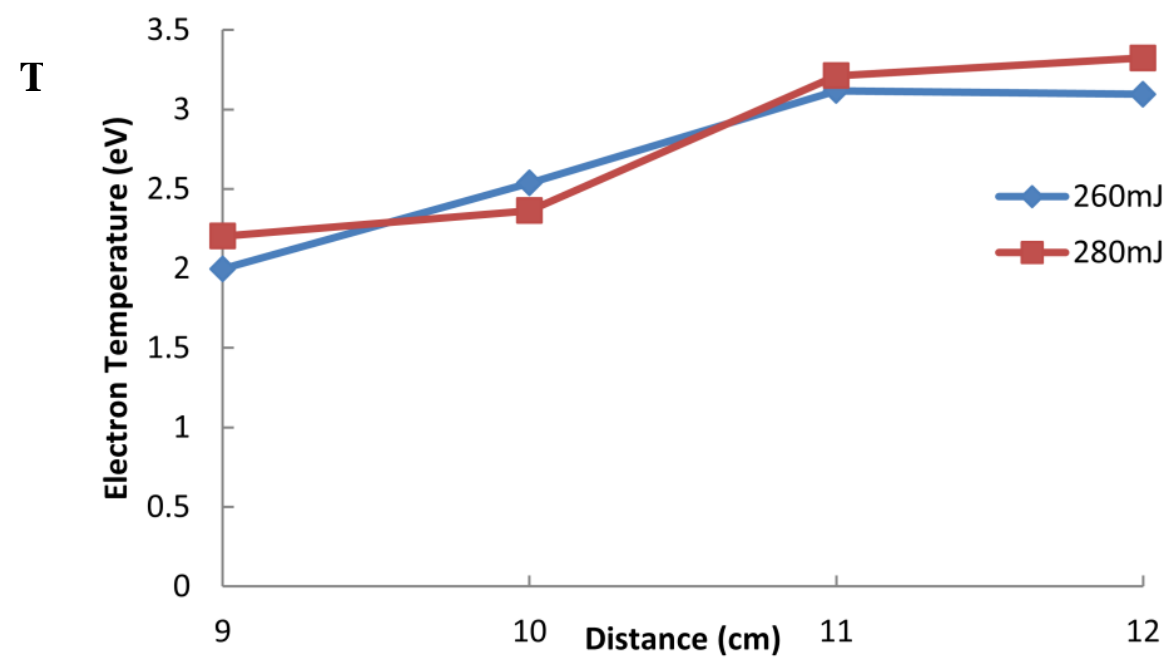

Figure 6- Variation of electron temperature with the distance from lead surface at variable laser energies.

It is observed from figure (6) that electron temperature has minimum value near the lead target and increases with increasing the distance of the focusing lens from the target surface. The temperature of the electron was increased from 1.99 to $3.1 \mathrm{eV}$ when the laser energy was $260 \mathrm{~mJ}$ and from 2.2 to $3.3 \mathrm{eV}$ when the laser energy became $280 \mathrm{~mJ}$. This result means that the thermal energy of electrons was rapidly converted into kinetic energy near the surface of the target. The increase of $\mathrm{T}_{e}$ with increasing the distance between the focusing lens and the target is strongly dependent on the spot size in the laser-induced plasma. When the lens-totarget distance is small (large spot size), the plasma spreads in the lateral and axial directions 
due to the laser's greater cone angle, forming a spherical structure. When the gap is wide (small spot size), however, the plasma's vertical axis ratio decreases, resulting in a stream-like shape. The absorption of the tailing of the laser pulse energy is different since the entire plasma is heated to a higher temperature by the tailing of the laser pulse. The different lensto-target distances produce the different shapes of the plasma. Furthermore, the majority of the energy from the laser pulse's tailing is absorbed by the plasma's front component, while a portion of the tailing pulse's energy is consumed to further ionize the plasma.

For the calculation of the number density of electron, we assume that the generation plasma must satisfy the local thermal equilibrium condition (LTE). Stark broadening represents the broadening of the spectral lines and the shift of the wavelength which occurs from the collision between the emitting atoms with the ions and electrons of plasma particles. This type of broadening is the most widely used to evaluate of $n_{e}$, as in the following equation $[8,12]$ :

$$
\mathrm{n}_{\mathrm{e}}=\left(\Delta \lambda_{1 / 2} \times 10^{16}\right) / 2 \mathrm{~W}
$$

where $\Delta \lambda_{1 / 2}$ is the full width at half maximum (FWHM) of the emission line based on Stark broadening and $\mathrm{W}$ is the electron impact parameter, which was described in details by Griem [13]. According to equation (2), the electron number density is calculated versus the distance of the target from $\mathrm{Pb}$ surface for different laser energies. Widths and intensities of the observed $\mathrm{Pb}$ emission lines are directly linked with laser energy and both quantities are directly proportional to each other. Figure (7) demonstrates the variation in electron number density with the distance between the focusing lens and the target surface at different pulse laser energies.

One can depict that the number density of electrons varies with the distance from target surface of both laser energies. The electron number density first increased to a maximum value at the distance of $11 \mathrm{~cm}$ and then reduced far away from the laser target at both laser energies. The value of $n_{e}$ increased sharply from $7.59 \times 10^{16} \mathrm{~cm}^{-3}$ to $1.09 \times 10^{17} \mathrm{~cm}^{-3}$ for $260 \mathrm{~mJ}$ and from $4.81 \times 10^{16} \mathrm{~cm}^{-3}$ to $1.49 \times 10^{17} \mathrm{~cm}^{-3}$ for $280 \mathrm{~mJ}$. Then, it decreased from $1.09 \times 1017$ $\mathrm{cm}^{-3}$ to $9.25 \times 10^{16} \mathrm{~cm}^{-3}$ for $260 \mathrm{~mJ}$ and from $1.49 \times 10^{17}$ to $1.12 \times 10^{17} \mathrm{~cm}^{-3}$ for $280 \mathrm{~mJ}$. The increase of $n_{e}$ is expected to occur due to the fact that plasma particles absorb laser photons through the inverse Bremsstrahlung process and then cause heat in the plasma plume, which causes the ionization of air around the target. This result agrees with the results reported earlier[14].

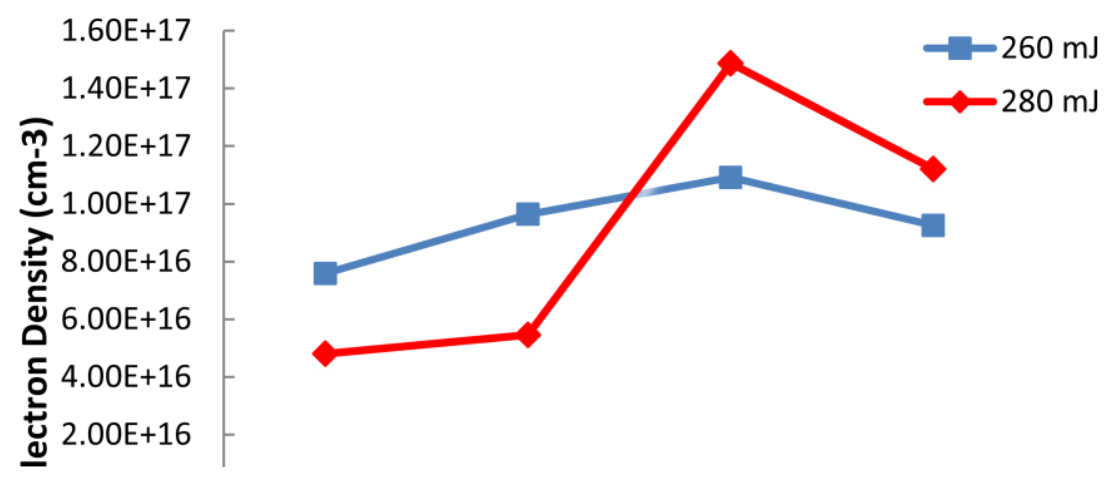

Figure 7-Variation of electron density with distance between focusing lens and target surface for different laser energies.

\section{Conclusions}

In this work, Pb plasma was induced by using Q-switched Nd:YAG laser at the fundamental wavelength with different energies resolved at different lens-target distances. The emission 
spectrum of $\mathrm{Pb}$ plasma shows only transitions of neutral lead. Also, a weak peak of hydrogen molecule appears in this spectrum in all laser pulse energies and lens-to-target distances under study. The emission intensity of plasma spectra increases with the increase in the laser-target distance. The temperature of the electron, determined by the Boltzmann plot method, is raised far away from the target in all laser energies under study. Electron number density, calculated by Stark broadening parameter, increases to maximum at $11 \mathrm{~cm}$ distance from the target surface using both laser energies under study.

\section{References}

[1] Dawood, M. S. and Margot, J. "Effect of ambient gas pressure and nature on the temporal evolution of aluminum laser-induced plasmas", Aip Advances, vol. 4, pp. 037111, 2014.

[2] Asamoah, E. and Hongbing, Y. "Influence of laser energy on the electron temperature of a laser-induced Mg plasma", Applied Physics B, vol. 123, no. 22, pp. 1-6, 2017.

[3] Cristoforetti, G. and Tognoni, E. "Calculation of elemental columnar density from self-absorbed lines in laser-inducedbreakdown spectroscopy: A resource for quantitative analysis", Spectrochimica Acta Part B, vol. (79-80), pp. 63-71, 2013.

[4] Hongbing, Y. Asamoah, E. Jiawei, C. Dongqing, Y. and Fengxiao, Y. "Comprehensive Study on the Electron Temperature and Electron Density of Laser-Induced Mg Plasma", Journal of Lasers, Optics \& Photonics, vol. 5, no. 2, pp. 1-6, 2018.

[5] Guo, k. Chen, A. Xu, W. Zhang, D. and Jin, M. "Effect of sample temperature on time-resolved laser-induced breakdown spectroscopy", AIP Advances, vol. 9, pp. 065214, 2019.

[6] Wang, Y. Chen, A. Li, S. Ke, D. Wang, X. Zhang, D. Jiang, Y. and Jin, M. "Influence of distance between sample surface and focal point on spectral intensity of nanosecond laserinduced silicon plasma in air", AIP Advances, vol. 7, pp. 095204, 2017.

[7] Wang, Y. Chen, A. Wang, Q. Sui, L. Ke, D. Cao, S. Li, S. Jiang, Y. and Jin, M. "Influence of distance between focusing lens and target surface on laser-induced $\mathrm{Cu}$ plasma temperature", Physics of Plasmas, 2018, 25:033302.

[8] F. Anabitarte, A. Cobo, and J.M. Lopez-Higuera, "Laser-Induced Breakdown Spectroscopy: Fundamentals, Applications, and Challenges", International Scholarly Research Network Spectroscopy, vol. 2012, pp. 1-12, 2012.

[9] Safeen, A. Shah, W. Khan, R. Shakeel, A. Iqbal, Y. Asghar, G. Khan, R. Khan, G. Safeen, K. and Shah, W. "Measurement of plasma parameters for copper using laser induced breakdown spectroscopy", Digest Journal of Nanomaterials and Biostructures, vol. 14, no. 1, pp. 29 - 35, 2019.

[10] Q. A. Abbas, "Effect of Target properties on the Plasma Characteristics that produced by Laser at Atmospheric Pressure", Iraqi Journal of Science, vol. 60, no. 6, pp. 1251-1258, 2019.

[11] Unnikrishnan, V. Alti, K. Kartha, V. Santhosh, C. Gupta, G. and Suri, B. "Measurements of plasma temperature and electron density in laser-induced copper plasma by time-resolved spectroscopy of neutral atom and ion emissions", PRAMANA ${ }^{\circ} \mathrm{C}$ Indian Academy of Sciences, vol. 74, no. 6, pp. 983-993, 2010.

[12] Cristoforetti, G. Legnaioli, S. Pardini, L. Palleschi, V. Salvetti, A. Tognoni, E. "Spectroscopic and shadowgraphic analysis of laser induced plasmas in the orthogonal double pulse pre-ablation configuration", Spectrochimica Acta, Part B, vol. 61, pp. 340-350, 2006.

[13] Griem,H. Principles of Plasma Spectroscopy", Cambridge Uni. Press, Cambridge, 1977.

[14] Issac, R.C. Varier, G.K. Gopinath, P. Harilal, S.S. Nampoori, V.P.N. Vallabhan, C.P.G. "Prompt electron emission and collisional ionization of ambient gas during pulsed laser ablation of silver", Applied PhysicsMaterials Science \& Processing A, vol. 67, pp. 557-561, 1998. 